\title{
Endoscopic magnet-assisted gastrojejunostomy to treat symptoms caused by a deformed pylorus
}

A 42-year-old woman presented with a 5 -year history of abdominal distension, abdominal pain, and emesis, which became worse after she began eating a little more. Gastroduodenal barium examination detected a deformed pylorus ( Fig. 1 a). Subsequently, a gastroduodenoscopy was performed, which revealed that the outlet of her stomach lay on the lesser curvature side of the gastric angulus, with a blind end at the antrum ( $\vee$ Fig.1b). We therefore suggested to the patient that she undergo surgery; however, she declined to undergo such treatment, preferring instead an endoscopic method to treat her problems. In the end, we decided to attempt, with the patient's informed consent, an endoscopic magnet-assisted gastrojejunostomy ( $\triangleright$ Video 1 ).

Firstly, two ring-shaped magnets (16$\mathrm{mm}$ diameter) with attached fixing strings were placed in succession into her jejunum and stomach ( $\mathbf{F i g} \cdot \mathbf{2} \mathbf{a}, \mathbf{b}$ ). After several attempts to adjust their position under fluoroscopic guidance, the two magnets attracted perfectly and were then stabilized by the string ( $\triangleright$ Fig. $\mathbf{2 c , d}$ ). After 1 week with the magnets in place, a superficial ulcer developed under the compression of the magnets ( $\triangleright$ Fig.2e). We extracted the magnets after another 2 weeks ( $\triangleright$ Fig. 2 f), leaving behind a stenotic fistula. We then used a dilation balloon to enlarge the fistula ( Fig. 3 a,b) and put in a $16 \times 20-\mathrm{mm}$ lumen-apposing metal stent ( $\triangleright \mathbf{F i g . 3 c}$ ). A subsequent endoscopy and barium examination showed that this manually built channel was unobstructed ( $>$ Fig. 3 $\mathbf{d}-\mathbf{f})$, with no leakage of barium. During 1 month of follow-up, the patient gained relief of her symptoms, without any complications of the procedure.

With advancements of technology, endoscopic methods, such as magnets, natural orifice transluminal endoscopic surgery (NOTES), and endoscopic ultrasound (EUS)-guided techniques, are able
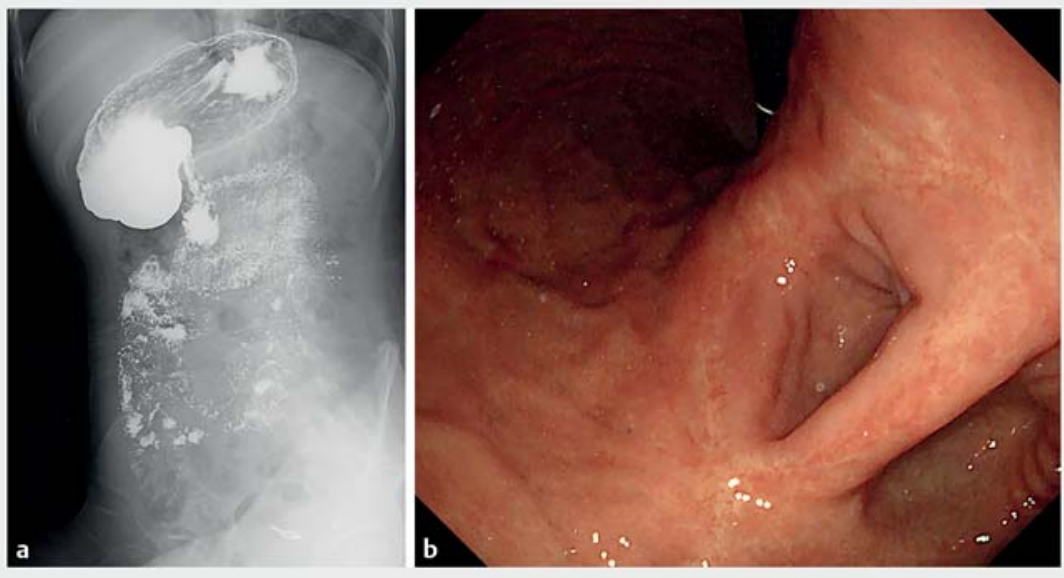

- Fig. 1 Images from a 42-year-old woman with a history of abdominal distension, abdominal pain, and emesis showing a deformed pylorus: $\mathbf{a}$ on barium examination; $\mathbf{b}$ on endoscopy.

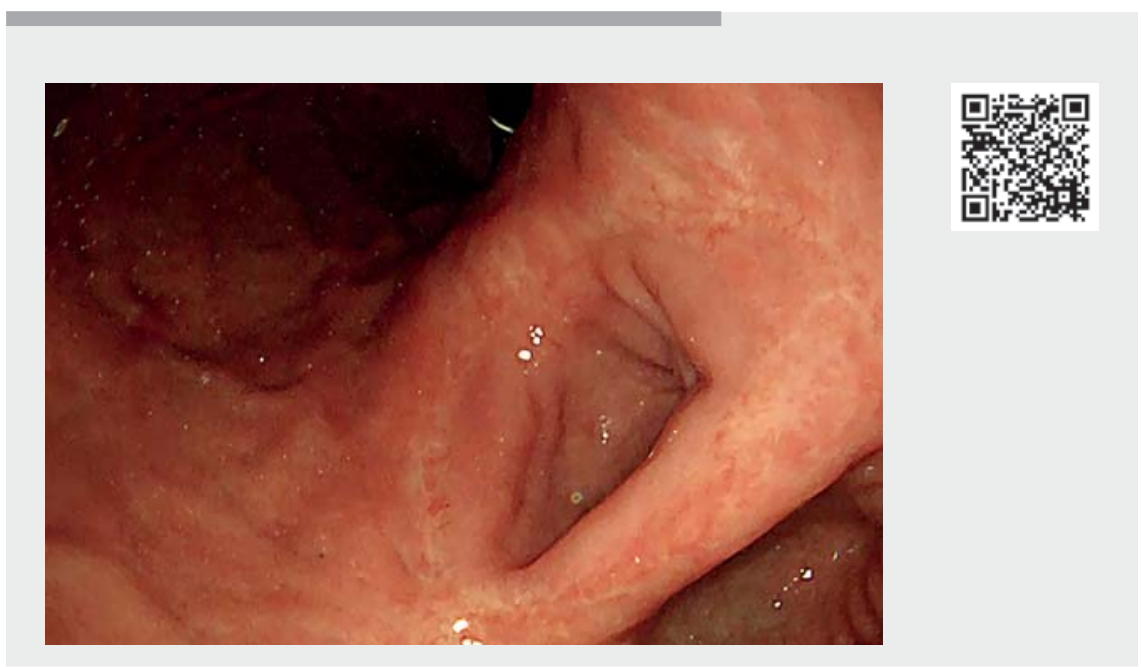

$\checkmark$ Video 1 Video showing a deformed pylorus identified in a 42-year-old woman with a history of abdominal distension, abdominal pain, and emesis; the procedure of endoscopic magnet-assisted gastrojejunostomy; and the subsequent dilation and stenting of the fistula to leave an unobstructed channel.

to create a gastrointestinal anastomosis without the requirement for surgery [1]. Moreover, the creation of magnet-assisted gastroenteric anastomoses has been demonstrated to be feasible and safe for malignant gastric outlet obstruction [2]. Our experience indicates that this meth- od may also result in good outcomes for patients with benign anatomic abnormalities.

Endoscopy_UCTN_Code_TTT_1AO_2AN 

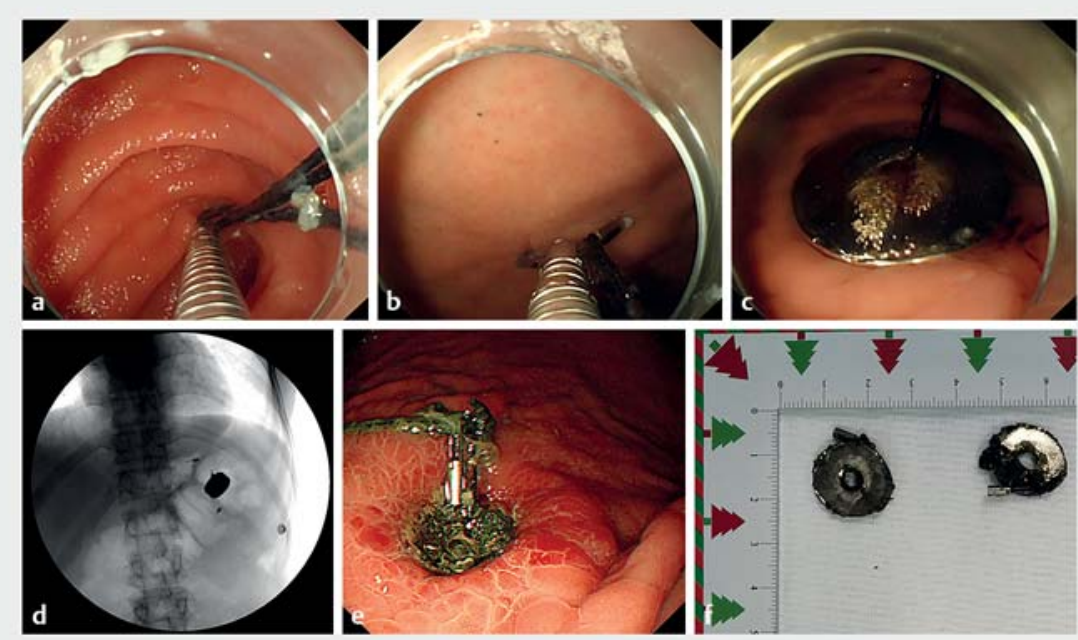

- Fig. 2 Images of the endoscopic magnet-assisted gastrojejunostomy procedure showing: $\mathbf{a}, \mathbf{b}$ endoscopic views of the two ring-shaped magnets with attached strings being placed into the jejunum and stomach in succession; $\mathbf{c}, \mathbf{d}$ the two magnets after perfect attraction had been achieved between them on: $\mathbf{c}$ endoscopic view; $\mathbf{d}$ radiographic image; $\mathbf{e}$ the superficial ulcer that developed under compression from the magnets; $f$ the two magnets following their extraction.
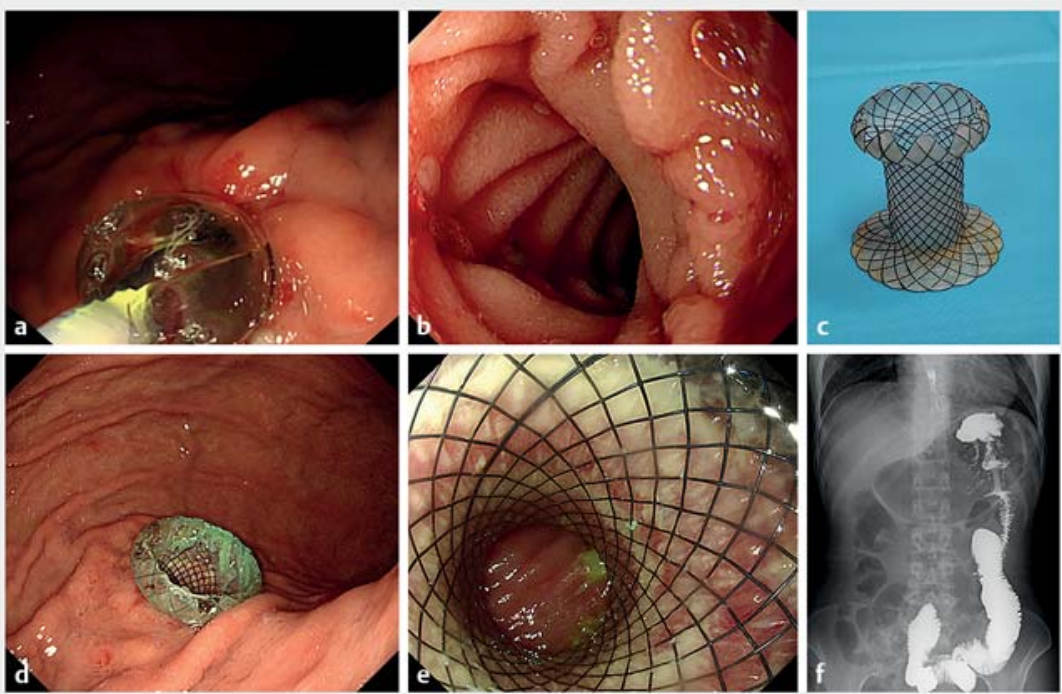

- Fig. 3 Images of the creation of the manually built channel showing: a the stenotic fistula being enlarged by balloon dilation; $\mathbf{b}$ the appearance of the fistula after dilation; $\mathbf{c}$ the lumenapposing metal stent that was inserted across the dilated fistula; $\mathbf{d}$, e endoscopic appearance 3 weeks later; $\mathbf{f}$ an unobstructed channel on barium examination.

\section{Funding}

1.3.5 project for disciplines of excellence, West China Hospital, Sichuan University ZYJC21011

\section{Competing interests}

The authors declare that they have no conflict of interest.
The authors

Long $\mathrm{He}^{1^{*}}$, Xiaobo Qin ${ }^{2 *}$, Liansong $\mathrm{Ye}^{1}$, Bing $\mathrm{Hu}^{1} \odot$

1 Department of Gastroenterology, West China Hospital, Sichuan University, Chengdu, Sichuan, China

2 Gastroenterology Department of Sichuan Provincial Disabled Revolutionary Armyman Hospital, Chengdu, Sichuan, China

\section{Corresponding author}

\section{Bing $\mathrm{Hu}, \mathrm{MD}$}

West China Hospital, Sichuan University, No. 37, Guo Xue Alley, Wuhou District, Chengdu City, Sichuan Province, China hubingnj@163.com

\section{References}

[1] Marrache MK, Itani MI, Farha J et al. Endoscopic gastrointestinal anastomosis: a review of established techniques. Gastrointest Endosc 2021; 93: 34-46

[2] van Hooft JE, Vleggaar FP, Le Moine O et al. Endoscopic magnetic gastroenteric anastomosis for palliation of malignant gastric outlet obstruction: a prospective multicenter study. Gastrointest Endosc 2010; 72: 530-535

\section{Bibliography}

Endoscopy 2022; 54: E546-E547

DOI 10.1055/a-1682-6815

ISSN 0013-726X

published online 15.11.2021

(c) 2021. Thieme. All rights reserved.

Georg Thieme Verlag KG, Rüdigerstraße 14 70469 Stuttgart, Germany

\section{ENDOSCOPY E-VIDEOS}

https://eref.thieme.de/e-videos

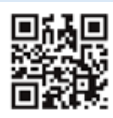

Endoscopy E-Videos is an open access online section, reporting on interesting cases and new techniques in gastroenterological endoscopy. All papers include a high quality video and all contributions are freely accessible online. Processing charges apply (currently EUR 375), discounts and wavers acc. to HINARI are available.

This section has its own submission website at

https://mc.manuscriptcentral.com/e-videos

* Joint first authors 